\title{
The Rise of Post-Confucian Knowledge Economies
}

\author{
SIMON MARGINSON
}

Simon Marginson is professor of higher education at the University of Melbourne, Australia. His recent books include Higher Education in the Asia Pacific: Strategic Responses to Globalization (Springer, 2011), edited with Sarjit Kaur and Erlenawati Sawir. E-mail: s.marginson@unimelb.edu.au.

Universities and research in East Asia and Singapore have been completely transformed over the last 15 years. On present trends, these higher education systems are on course to share global leadership with institutions in the English-speaking countries and western Europe.

There is much rhetoric about the rise of Asian knowledge economies-both admiring and (in some quarters) half fearful as well, and not all of it is accurate. For example, education and research outside East Asia-including India and Southeast Asia-are well behind the progress of East Asia and Singapore at this stage. Progress is being made, and there are pockets of real strength—as in research in Thailand and in Malaysia's customer friendly private colleges.

Nevertheless, in China, Hong Kong, Taiwan, South Korea, and Singapore the true global change is taking place. These systems are joining Japan, which has sustained a front-rank, high-participation science and engineering system for more than three decades and was the second largest research and development investor in the world, until passed by China recently. 


\section{RESEARCH LEADERS}

The momentum of East Asia's knowledge economies is based on the record in the data on research performance and educational participation. It can also be observed through research. Recently, I completed an Australian Research Council-funded comparison of the global links and capacities of leading research universities in the Asia Pacificincluding 16 case studies in 15 different higher education systems in the region.

The case-study universities included the University of Tokyo in Japan, Seoul National University in Korea, Peking and Shanghai Jiao Tong University in China, Taiwan National University, the University of Hong Kong, and the National University of Singapore. Each already plays an important global role and has a larger future.

The University of Tokyo produces as many science papers as any US university, except Harvard University. Peking University (Beida) is at the heart of China, and Shanghai Jiao Tong produces the third-largest number of papers in China after Zhejiang and Tsinghua University. On several indicators, Taiwan National University is currently the top-performing Chinese university. The National University of Singapore is a byword for effective global strategy and partnerships. Hong Kong University is the largest of five universities in the Hong Kong Special Administration Region with impressive research credentials. Seoul National University is the fifth university in the world, in alumni with chief executive officer positions in Fortune 500 US enterprises.

\section{Post-CONFUCIAN}

It is significant that though there are many differences between them, all of these systems have Sinic cultural roots. The outlier in Southeast Asia, Singapore, has a plural cultural composition but the Chinese influence is strong. All have been shaped by the 
deep Confucian commitment to education in the family, which underpins the quality of schooling, ensuring that advances in participation are matched by advances in student learning. These nations lead the world in the Organization for Economic Cooperation and Development's survey of the learning achievement of 15-year-olds-Program for International Student Assessment.

All, whether in one-party states or plural polities—-like Korea, Japan, and Taiwanbenefit from strong, effective state machines that invest heavily in education and research capacity, target that investment to goals, and follow through to ensure those goals are achieved. Only in Japan, where the earlier dynamism has fallen away, has investment leveled off. The Post-Confucian higher education systems are a remarkable combination of resilient tradition and Western science. They are ushering in a new hybrid East-West modernity.

Higher education in East Asia and Singapore is advancing rapidly on three fronts at once: the overall rate of participation in tertiary education-now exceeding 85 percent in Taiwan and South Korea-the quality of leading universities, and rapidly growing research and development, within taxation and public spending low by world standards. The achievement rests on economic growth. All except China have reached western European levels of wealth. According to the World Bank, Gross National Income per head in 2010 was US\$29,010 in South Korea, US\$47,130 in Hong Kong, and US\$55,380 in Singapore. It was US\$34,780 in Japan.

\section{CHINA RISING}

In China the gross national income per head was just US $\$ 7,570$, but this had doubled in five years; and amid gross inequalities Beijing, Shanghai, and parts of Eastern China are much wealthier. It is planned that the participation in tertiary education will reach 40 
percent by the year 2020. Participation was just 5 percent in 1990. Regional differences are a continuing problem, however.

China plans to boost research and development spending to 2.5 percent of gross domestic product by 2010. Spending on research is already at 40 percent of the level applying in the United States. In the last decade the number of science papers has grown by 17 percent a year.

China's research trajectory is not free of problems. Arguably, there is too much research in state enterprises and not enough in the universities. Problems occur of bureaucratic interference in decisions about research grants, and the feisty debate inside Chinese universities is not matched by free conversation outside in civil society. China's publication numbers are not yet matched by a parallel performance in highly cited papers.

But research output in China is growing by leaps and bounds, and in some fieldssuch as chemistry, engineering, and materials-China clearly excels in world terms. Physics and maths are also strong, as elsewhere in East Asia. Life sciences and medicine are less developed.

All in all, East Asian research universities have a way to go yet. According to the Leiden University data, on 2005-2009 science paper output, in Asia and the Western Pacific, 18 universities produced more than 5,000 papers and had at least 10 percent of all papers in the top-tenth in their field in citation rate-6 in each of China and Australia, 2 in each of Singapore and Hong Kong, and 1 in each of Japan and Korea. The equivalent number of universities in Europe was 47 and in the United States 64.

However, 38 Asia Pacific universities produced more than 5,000 papers. Cite rates are improving. Given the continuing growth of investment in research, it looks likely the Post-Confucian systems will make it. 